\title{
Bringing Empathy into Play: On the Effects of Empathy in Violent and Nonviolent Video Games
}

\author{
Christian Happ, André Melzer, and Georges Steffgen \\ Université du Luxembourg, Campus Walferdange, L-7201 Walferdange, Luxembourg \\ \{christian.happ, andre.melzer, georges.steffgen\}@uni.lu
}

\begin{abstract}
While violent media has adverse effects on cognition, emotion and behavior, prosocial content promotes these variables in a prosocial way. Greater individual levels of empathy as well as increasing the level of empathy in media content typically foster prosocial behavior and reduce aggression. Two experiments replicated game content findings, and also showed that inducing empathy prior to a video game had a positive influence on behavior. However, under certain circumstances, inducing empathy before playing a violent video game may even have negative effects on behavior. As empathy is a common tool in prevention programs, the implications of these findings are discussed.
\end{abstract}

Keywords: video games, empathy, aggression, prosocial behavior.

\section{Prosocial and Antisocial Effects of Video Games}

In a recent overview, Anderson and his colleagues [1] confirmed that video game violence exposure is positively related to indicators of aggression. Furthermore, violent video game exposure was also significantly related to lower levels of prosocial (i.e., helping) behavior and a decrease in empathy. Recent studies found that prosocial video games reduce aggressive cognitions [2] and enhance prosocial behavior (cf. [3]). These findings can be explained by the General Learning Model (GLM, [4]), which addresses both negative and positive effects of media use and proposes that games teach something to media users (regardless of content), and that the valence of this content matters. In sum, video games as a medium with the highest level of interactivity appear to provide the ground for both prosocial and antisocial learning.

\section{Empathy, Entertainment Media, and Behavioral Consequences}

Cohen and Strayer [5] define empathy as "the ability to understand and share in another's emotional state or context" (p.988). The perception of the concept of empathy varies from an emotional response to others' feelings to the cognitive ability to understand these feelings. In addition to these two often-used major components of cognitive and affective empathy, a dimension for empathy in fictional contexts broadens the concept [6]. Empathy is typically associated with positive effects like, for example, a higher willingness to help others but negatively related to aggressive behavior [7]. With regard to exposure to media violence, it has been shown that 
playing violent video games increases physical aggression, but reduces affective empathy [8]. Similar results have been reported regarding identification with aggressive game characters, while shifting the focus towards the victim of violence in the game may have a beneficial effect in terms of decreasing aggressive behavior [9]. Identification with a media or game character may therefore either foster or reduce aggressive tendencies depending on the particular content. To date, however, only few studies manipulated the level of empathy in media content and show indeed positive, that is, aggression-reducing, prosocial effects [7].

\section{Study 1: Empathy Induction in a Prosocial versus Violent Game}

Based on the findings mentioned above, playing a prosocial video game should lead to more prosocial and less antisocial behavior compared to a violent video game. Similarly, reading an empathy-related text should lead to stronger empathetic reactions and more prosocial behavior compared to a neutral text. Regarding the interaction of both factors, it was expected that empathy might compensate for the negative effects of playing a violent video game. All hypotheses were tested with onesided analyses of variances (ANOVAs). Eighty students $\left(55 \%\right.$ females, $\left.M_{\text {Age }}=23.4\right)$ read a bogus newspaper article on the beneficial effect of video games on memory and were offered either no explanation (neutral condition) or this effect was attributed to emotional involvement and empathy in video games (empathy condition). Next, participants used the Nintendo Wii ${ }^{\circledR}$ game console to play either the prosocial video game Trauma Center 2: New blood or the violent video game Manhunt 2 for 10 minutes. Participants were then allowed to take a reward for participating, which was placed outside the lab. Finally, they were handed an envelope containing a questionnaire, which completion would be optional and not controlled. This measured their actual prosocial (returning the questionnaire) and antisocial behavior ("stealing" more than one piece) in an externally valid way.

As expected, the violent video game led to less prosocial behavior $(M=10 \%)$ than the prosocial game $\left(M=31 \% ; \chi^{2}(1)=5.52, p=.02, d=0.70\right)$. Similarly, Manhunt 2 led to more antisocial behavior $(M=1.29, S D=1.42)$ than Trauma Center $(M=0.77, S D=0.96$; $\left.F(1,76)=3.47, p=.03, \eta^{2}=.44\right)$. In other words, people playing the prosocial Trauma Center were more likely to take just the amount of reward they were allowed and were more likely to deliver the envelope. Hence, prosocial media content was shown to trigger prosocial behavior while violent media content triggered antisocial behavior. However, regarding the newspaper article participants read (empathyrelated or neutral), no significant difference was observed for prosocial behavior $\left(M_{\text {Empathy }}=20.5 \%\right.$; and $\left.M_{\text {Neutral }}=19.5 ; \chi^{2}(1)=0.01, p=.57\right)$ or antisocial behavior $\left(M_{\text {Empathy }}=1.12, S D=1.38\right.$; and $\left.M_{\text {Neutral }}=0.95, S D=1.07 ; F(1,76)=0.27, p=.60\right)$. When looking at the interaction between game and text, the analyses for antisocial $(F(1,76)=0.56, p=.46)$ and prosocial behavior $(F(1,76)=2.39, p=.12)$ were also nonsignificant. However, it seemed that the empathy-stimulating text (compared to neutral) fostered prosocial behavior after the prosocial game (from $25 \%$ to $37 \%$ helpers), but led to less helping after the violent game (from $16 \%$ to $5 \%$ helpers). 


\section{Study 2: Empathy Induction and Playing Perpetrator or Victim}

In Study 2 empathy was induced by means of a short clip. It was expected that watching this clip prior to playing a violent video game should increase players' moral concerns and foster their prosocial behavior. In addition, we assumed that the role of the character would play a role: Compared to playing the victim from the previous clip, playing the perpetrator should result in stronger levels of moral concerns in the game. In addition, prosocial behavior was expected to be highest for participants, who had seen the empathy-stimulating clip and played the victim. All hypotheses were tested with one-sided analyses of variances (ANOVA). Eighty students $\left(69 \%\right.$ females, $\left.M_{\text {Age }}=21.8\right)$ either watched a neutral (excerpt from "The Last Emperor") or an empathy clip (an emotional kidnapping sequence from the movie "Street Fighter-The Legend of Chun-Li"). Next, participants played either the victim or the perpetrator from the clip in the corresponding video game Streetfighter IV using the Sony PlayStation ${ }^{\circledR} 3$ console for 15 minutes. At the end, participants were remunerated 5 Euros in coins and told that a donation box for a good cause would be placed outside the lab. Whether and how much participants donated were used as indicators of prosocial behavior.

Results for prosocial behavior and moral concerns were in line with our expectations. Participants who had watched the empathy clip donated more often $(M=85 \%)$ than those who had seen the neutral clip $\left(M=68 \% ; \chi^{2}(1)=3.38, p=.06\right.$, $d=0.42$ ), however, slightly failing to reach significance. Participants in the empathy clip condition also reported having more moral concerns $(M=1.80, S D=0.88)$ than those in the neutral condition $\left(M=1.35, S D=0.62 ; F(1,76)=7.75, p=.00, \eta^{2}=.09\right)$. It appears that a short clip was sufficient to entail changes in the perception of a violent video game and significantly affected people's decision to engage in prosocial behavior.

When looking at the interactions between type of clip and game character, only for those playing the victim, the empathy clip led to an almost significant raise in donating behavior $\left(\chi^{2}(1)=3.58, p=.06, d=0.63\right)$. Because experiencing either a victory or a loss may have additionally affected the players, their status as winner or loser was added as an additional variable. This 3-way-interaction was significant with respect to the amount players donated $\left(F(1,72)=4.18, p=.04, \eta^{2}=.06\right)$. Having previously played the victim led to five times higher donations $(M=3.00, S D=1.41)$ compared to players of the perpetrator $(M=0.60, S D=0.34)$. In contrast to our expectation, it appears that the effects of empathy largely depend on the game character and the game outcome.

\section{General Discussion and Concluding Remarks}

Study 1 replicated findings (e.g. [1]) that prosocial game content triggered prosocial behavior whereas violent content led to antisocial behavior. With regard to empathy, a fictitious text was not powerful enough to foster prosocial behavior after playing a "good" (i.e., prosocial) game, or to increase detrimental effects after playing a "bad" (i.e., violent) video game. In Study 2, with a stronger induction, however, empathy induced through a video clip had a substantial impact: This clip shown prior to 
playing a beat 'em up game led to more prosocial behavior and an increase in moral concerns after playing the game. The interaction of clip and game character showed the differential effect empathy induction could have. While empathy induction had the expected effects on player's feelings (i.e., moral concerns), winning in the "bad guy" condition led to even less prosocial behavior. This finding, for example, is in line with earlier findings of higher identification with mean characters, which leads to more violence [9]. However, it is still unexpected as empathy is generally promoted as a help-oriented tool aimed at reducing aggression and fostering prosocial behavior [10].

In sum, the present study corroborates a very differential role of empathy in the media context. Further research in this field is urgently needed, as our findings challenge the conventional characterization of the nature of media content. Evidently, simple classifications in either "good" or "bad" forms of entertainment media are overly shortsighted.

\section{References}

1. Anderson, C.A., Shibuya, A., Ihori, N., Swing, E.L., Bushman, B.J., Sakamoto, A., Rothstein, H.R., Saleem, M.: Violent video game effects on aggression, empathy, and prosocial behavior in Eastern and Western countries: A meta-analytic review. Psych. Bull. 136, 151-173 (2010)

2. Greitemeyer, T., Osswald, S.: Prosocial video games reduce aggressive cognitions. J. Exp. Soc. Psych. 45, 896-900 (2009)

3. Gentile, D.A., Anderson, C.A., Yukawa, S., Ihori, N., Saleem, M., Ming, L.K., et al.: The effects of prosocial video games on prosocial behaviors: International evidence from correlational, experimental, and longitudinal studies. Pers. Soc. Psychol. B 35, 752-763 (2009)

4. Buckley, K.E., Anderson, C.A.: A theoretical model of the effects and consequences of playing video games. In: Vorderer, P., Bryant, J. (eds.) Playing Video Games: Motives, Responses, and Consequences, pp. 363-378. LEA, Mahwah (2006)

5. Cohen, D., Strayer, J.: Empathy in Conduct-Disordered and Comparison Youth. Dev. Psych. 32, 988-998 (1996)

6. Leibetseder, M., Laireiter, A.-R., Köller, T.: Structural analysis of the E-scale. Pers. Indiv. Differ. 42, 547-561 (2007)

7. Konijn, E.A., Nije Bijvank, M., van der Heijden, Y.A., Walma van der Molen, J.H., Hoorn, J.F.: Babies against bullets: Empathy as an intervention technique in violent video game play. In: International Communication Association, Annual Meeting, Montreal, Quebec (2008)

8. Krahé, B., Möller, I.: Longitudinal effects of media violence on aggression and empathy among German adolescents. J. Appl. Dev. Psychol. 31, 401-409 (2010)

9. Konijn, E.A., Nije Bijvank, M., Bushman, B.J.: I wish I were a warrior: The role of wishful identification in the effects of violent video games on aggression in adolescent boys. Dev. Psych. 43(4), 1038-1044 (2007)

10. Batson, C.D.: The altruism question: Toward a social-psychological answer. Erlbaum, Hillsdale (1991) 